\title{
Comparison of the hypoglycemic and antithrombotic (anticoagulant) actions of whole bovine and camel milk in streptozotocin-induced diabetes mellitus in rats
}

\author{
Aida A. Korish, ${ }^{1 *}$ ৫) Abdel Galil M. Abdel Gader, ${ }^{2}$ and Abdulqader A. Alhaider ${ }^{3}$ \\ ${ }^{1}$ Physiology Department, College of Medicine, King Saud University, 11461 Riyadh, PO Box 2625, Saudi Arabia \\ ${ }^{2}$ Physiology Department, College of Medicine, Al Faisal University, 11533 Riyadh, PO Box 50927, Saudi Arabia \\ ${ }^{3}$ Pharmacology Department, College of Medicine, King Saud University, 11461 Riyadh, PO Box 2625, Saudi Arabia
}

\begin{abstract}
People with diabetes are at higher risk of fatal thromboembolic accidents in the cerebral and coronary circulations, especially stroke and ischemic heart disease. We have previously described the hypoglycemic, hypolipidemic, and anticoagulant activity of orally administered camel milk in streptozotocin-induced diabetic rats. In the present study in the same animal model, we extended these observations by comparing camel milk and the more available and widely consumed bovine milk with respect to their antidiabetic and antithrombotic actions. Rats were rendered diabetic by intraperitoneal streptozotocin $(65 \mathrm{mg} / \mathrm{kg})$, and then camel milk or bovine milk was administered orally for $8 \mathrm{wk}$. We evaluated the changes in body weight, fasting blood glucose, glucose tolerance, blood coagulation profile, and platelet function. Diabetic rats developed weight loss, hyperglycemia, glucose intolerance, inhibition of platelet aggregation responses to arachidonic acid and adenosine diphosphate, a marked decrease $(>50 \%)$ in plasma fibrinogen levels, and short activated partial thromboplastin time. Treatment with camel milk or bovine milk reversed these abnormalities, resulting in weight gain, decreased blood glucose levels, and improved glucose tolerance. Despite the more remarkable antidiabetic action of camel milk, treatment with bovine milk was more effective in correcting plasma fibrinogen levels and restoring inhibited platelet aggregation responses. Long-term administration of camel milk or bovine milk counteracted streptozotocin-induced metabolic manifestations in rats, maintained platelet function, and abolished coagulopathy-associated fibrinogen consumption. Notably, the antidiabetic effect of camel milk was more pronounced than that of bovine
\end{abstract}

\footnotetext{
Received March 12, 2019.

Accepted August 30, 2019.

*Corresponding author: or iaidakorish@yahoo.comandakorish@ksu .edu.sa
}

milk, but bovine milk exhibited more potent anticoagulant activity than camel milk. These findings should encourage further clinical trials to assess the efficiency of camel milk and bovine milk or their derived peptides as food supplements or potential nonpharmacological therapies for dysglycemia and the vascular complications of diabetes mellitus.

Key words: camel milk, bovine milk, diabetes, antithrombotic action, platelet function

\section{INTRODUCTION}

Diabetes mellitus is a chronic metabolic disorder characterized by numerous abnormalities in carbohydrate, protein, and fat metabolism (ADA, 2014). It is also complicated by diverse biological, hemostatic, and thromboembolic cardiovascular problems in the form of accelerated coagulation, myocardial ischemia, heart failure, stroke, and peripheral vascular disorders (Low Wang et al., 2016). One of the prime hemostatic disorders in diabetes mellitus is increased platelet activity, which has been linked to hyperglycemia, hyperinsulinemia, insulin resistance, and inflammation (Kakouros et al., 2011; Paneni et al., 2013). Furthermore, oxidative stress, increased advanced glycation end products, and the lack of vasodilator effect of $\mathrm{NO}_{2}$ and prostacyclin all participate in endothelial damage and hemostatic activation, and promote atherosclerosis and thrombosis (Paneni et al., 2013).

Although glycemic control may improve some platelet abnormalities, antiplatelet therapy is widely used in people with diabetes to prevent atherosclerosis and thrombus formation (Nicolucci and Standl, 2011; Ogawa, 2008). This treatment has benefits in reducing the risk of the cardiovascular complications of diabetes, but is associated with increased risk of intracranial and gastrointestinal bleeding, especially in elderly patients. Resistance to dual antiplatelet therapy is also a problem, particularly aspirin and clopidogrel (Angiolillo et al., 2007). 
Recent years have witnessed growing interest in the use of natural products such as bovine and camel milk in the maintenance of general health and as alternative therapies for chronic health problems (Park and Haenlein, 2013). The diverse biological properties of bovine milk and the bioactive peptides derived from it have attracted much interest judging by the large number of published reviews (Bhat et al., 2015; Marcone et al., 2017; Sultan et al., 2018) and original studies (Manso et al., 2002; Shi and Gilbert, 2003). These biological properties have been proven to have strong potential health benefits in humans, including antithrombotic, anti-inflammatory, lipid-lowering, antihypertensive and immunomodulatory activity, and perhaps more.

People from India have used camel milk to treat multiple acute and chronic diseases, including asthma, tuberculosis, anemia, jaundice, spleen dysfunctions (Rao et al., 1970), and diabetes mellitus (Agrawal et al., 2003). Furthermore, camel milk has been used successfully to treat several autoimmune disorders, including Crohn's disease and multiple sclerosis (Aref, 2018). Sarfraz (2014) found that camel milk treatment in people infected with hepatitis $\mathrm{C}$ virus improved liver function, leading to an increase in plasma proteins levels and correction of platelet and white cell counts.

The hypoglycemic effect of camel milk has been extensively studied in humans and experimental animals (Agrawal et al., 2003, 2004). However, in a recent publication by our group (Korish et al., 2015), we demonstrated that streptozotocin (STZ) administration in healthy rats resulted in significant consumption of circulating fibrinogen (a soluble plasma protein that plays an integral role in the blood clotting mechanism; when acted upon by thrombin, it changes to insoluble fibrin, the main component of a blood clot) and loss of platelet aggregation responses to ADP and arachidonic acid; this effect was taken to indicate activation of the coagulation system and subsequent consumption coagulopathy. However, the administration of camel milk prevented these changes, resulting in the recovery of fibrinogen levels and he normalization of platelet aggregation responses. We suggested that this anticoagulant (antithrombotic) property of camel milk, which we identified for the first time, was not unexpected: similar biological effects have been identified and characterized in bovine milk (Chabance et al., 1995). The European Economic Community has granted a license to import camel milk (European Union, 2013), and the US Food and Drug Administration has approved the trade of camel milk (Camel Milk USA, 2015); both permits were presumably based on the nutritional and claimed health benefits of camel milk (Gader and Alhaider, 2016). This encouraged us to further our earlier observations on the anticoagulant antithrombotic proper- ties of camel milk (Korish et al., 2015), and undertake this study investigating comprehensively the metabolic effects of fresh camel and bovine milk. More specifically, we compared the antithrombotic action of the tested milk types on blood coagulation pathways in the same setting in a streptozotocin diabetes rat model. We included milk-treated healthy rat groups as positive controls to ensure safety and take into account any influence of the long-term ingestion of camel or bovine milk. This step provided a reliable basis for the comparison of the metabolic and anticoagulant effects of camel milk and bovine milk in animals with diabetes. This approach uncovered a very interesting finding: the more powerful anticoagulant action of bovine milk compared with camel milk in preventing the consumption of plasma fibrinogen levels and restoring platelet activity (adhesiveness) in diabetic rats, in which consumption coagulopathy was induced by STZ. This opens a new perspective for the therapeutic application of bovine milk or its bioactive peptides in preparing anticoagulant medications. It also reassures milk consumers that the beneficial effects of consuming camel milk and bovine milk go beyond their nutritional value and include prevention of the hypercoagulability that complicates diabetes mellitus and many other health conditions.

\section{MATERIALS AND METHODS}

\section{Animals and Experimental Design}

This case-control study was carried out on 6- to 8-wk-old male Wistar rats obtained from the Experimental Animal Care Center, College of Medicine, King Saud University, Riyadh, Saudi Arabia. The animals were housed in cages, each containing 4 rats in conditions of controlled humidity, room temperature, and 12-h light/dark cycles, with free access to standard rat chow and water. The rats were allowed to acclimatize to the laboratory conditions for $2 \mathrm{wk}$. Keeping in mind that both camel milk and bovine milk are widely consumed by the general population, including healthy people and people with a wide range of diseases, the current study aimed at comparing the 2 types of milk (with respect to their metabolic and antithrombotic properties) in healthy rats, as well as in rats with diabetes (type 1 diabetes mellitus). The study included 3 groups of healthy rats and 3 groups of diabetic rats (n $=10$ in each group) as follows: the control group (C) consisted of healthy rats receiving no treatment; the control camel-milk-treated group (CCM) consisted of healthy rats receiving camel milk; the control bovinemilk-treated group (CBM) consisted of healthy rats receiving bovine milk; the untreated diabetic group (D) consisted of STZ-induced diabetic rats receiving 
no treatment; the diabetic camel-milk-treated group (DCM) consisted of diabetic rats treated with camel milk; and the diabetic bovine-milk-treated (DBM) consisted of diabetic rats treated with bovine milk. The institutional review board of the College of Medicine, King Saud University, approved the study (IRB-KSU\# 9-704), and all experimental techniques were conducted according to the guidelines of the College of Medicine Research Center of King Saud University, which follows the international guidelines for the use and care of experimental animals.

\section{Induction of Diabetes Mellitus in Rats}

Type 1 diabetes mellitus was induced in groups D, DCM, and DBM by a single intraperitoneal injection of STZ (Sigma-Aldrich Inc., St. Louis, MO) at a dose of $65 \mathrm{mg} / \mathrm{kg}$, dissolved in $0.05 M$ sodium citrate, $\mathrm{pH}$ 4.5, as described elsewhere (Okazaki et al., 1997; Otero et al., 2005). Control groups C, CCM, and CBM were injected with a citrate buffer $(0.05 M$ sodium citrate, $\mathrm{pH}$ 4.5). Blood glucose levels were determined $72 \mathrm{~h}$ after STZ injection with an Accu-Chek blood glucose monitor (Roche Diagnostics, West Sussex, UK) using a drop of blood from the animal's tail vein. Animals were considered diabetic if their blood glucose was $\geq 250$ mg/dL (Karuna et al., 2011).

\section{Collection of Camel and Bovine Milk}

Fresh milk was collected daily, in the early morning, by manual milking of dromedary camels (Camelus dromedarius) of the white Nagdi breed and lactating cows, all kept in private camel and cattle farms outside Riyadh, Saudi Arabia. To standardize the quality of the milk used, the milked animals, their diet, and the time of milking were kept unchanged throughout the study. The collected milk was kept in sterile screw-capped bottles, transported to the laboratory in cool boxes immediately after collection, and used the same day.

\section{Chemical Composition of Camel and Bovine Milk}

We determined the humidity of the administered milk gravimetrically using a vacuum oven, and its ash content by incineration at $550^{\circ} \mathrm{C}$ for $4 \mathrm{~h}$ using $\mathrm{AOAC}$ methods (AOAC International, 2000). We assessed fat content gravimetrically using petroleum oil as a solvent according to AOCS methods (AOCS, 1998), and we determined protein levels using Lowry's method (Lowry et al., 1951). The humidity of the camel milk was $88.84 \%$, and the fat, protein and ash levels were $3.10,2.91$, and $0.79 \%$, respectively. The corresponding levels for bovine milk were $87.3,3.57,3.5$, and $0.87 \%$.

\section{Microflora Counts in Camel and Bovine Milk}

We undertook a standard plate count of aerobic bacteria using the pour plate method (Abera et al., 2016) and expressing the count in colony-forming units per milliliter $(\mathrm{cfu} / \mathrm{mL})$. Camel and bovine milk contained 2.9 and $3.1 \log _{10} \mathrm{cfu} / \mathrm{mL}$, respectively.

\section{Treatment of Rats with Camel and Bovine Milk}

Before starting the milk treatment, we conducted a pilot study to estimate the volume of milk that could be consumed by an adult rat per day and detect any abnormal reactions. We found that the rats could drink approximately $50 \mathrm{~mL}$ of milk per $24 \mathrm{~h}$ without noticeable adverse reactions. This dose has also been used previously (Agrawal et al., 2004). Groups CCM and DCM received camel milk, and groups CBM and DBM received bovine milk, $50 \mathrm{~mL} /$ day per rat, for $8 \mathrm{wk}$. The fresh milk was supplied every morning in clean bottle with a nozzle supported on the side of the cage. Rats were allowed to drink the milk freely, without concomitant food supplies, until they consumed all of the recommended milk dose. Then, regular rat food and water was provided and left in the cages until the next morning, when it was removed before the new milk dose was supplied. The animals in groups $\mathrm{C}$ and $\mathrm{D}$ were maintained on the standard rat chow and drinking water with no milk administration. We monitored BW and fasting blood glucose (FBG) levels in all animals at wk 0 and 8 of the study.

\section{Intraperitoneal Glucose Tolerance Test}

To compare the effects of camel milk and bovine milk on glucose tolerance in the control and diabetic rats, animals in all groups were subjected to an intraperitoneal glucose tolerance test (GTT) at the end of the study. Animals were deprived of food and milk overnight but were allowed free access to water. At 0 min of the intraperitoneal GTT, we determined FBG and then the animals received an intraperitoneal injection of $\mathrm{D}(+)$-glucose $1 \mathrm{~g} / \mathrm{kg}$ of BW dissolved in $2 \mathrm{~mL}$ of distilled water (Omer et al., 2004). Then, blood glucose levels were estimated at 15,30,45,60, 90, 120, and 150 min using the Accu-Chek blood glucose monitor (Roche Diagnostics) using a drop of blood from the tail vein.

\section{Blood Sample Collection for Hemostatic Tests}

After completion of the milk treatment period, fasting animals were anesthetized with Nembutal (50 mg/ $\mathrm{kg}$, intraperitoneal), and blood samples were collected 
from the retro-orbital venous plexus into $3.2 \%$ trisodium citrate tubes, to give a blood/citrate ratio of 9:1. The tubes were gently inverted to mix the blood with the anticoagulant. The samples were transferred immediately to the Coagulation Laboratory, College of Medicine, King Saud University, for platelet aggregation and coagulation tests. A coagulation technician checked the blood samples carefully for any sign of clot formation. The samples were centrifuged at $200 \times g$ for $8 \mathrm{~min}$, and the platelet-rich plasma was separated carefully using a plastic pipette and kept in a plastic tube. The remaining blood samples were centrifuged at $1,000 \times g$ for 15 min to prepare platelet-poor plasma. Before undertaking the aggregation studies in platelet-rich plasma, we adjusted the platelet count to $300,000-400,000$ platelets/ $\mu \mathrm{L}$ using a hemocytometer.

\section{Platelet Aggregation Tests}

We used an aggregometer (PAP4; Bio/Data, Horsham, PA) to test the aggregation of platelets in 180 $\mu \mathrm{L}$ of platelet-rich plasma after activation by $20 \mu \mathrm{L}$ of either ADP $(20 \mu \mathrm{mol} / \mathrm{L})$ or arachidonic acid $(1.64 \mathrm{mM}$; Bio/Data), which are the standard doses used in human studies and as detailed previously (Gader et al., 1990; Al-Mashhadani et al., 1997). The aggregometer recording paper is already scaled at $10 \%$ incremental lines to a maximum aggregation (MA) of $100 \%$. The individual sample aggregation response is picked directly from the recording paper as percentage maximum aggregation (MA\%).

\section{Coagulation Tests}

We assessed blood coagulation profiles using the STA compact automated coagulometer (Stago, Asnières sur Seine, France). We estimated prothrombin time, activated partial thromboplastin time (APTT) and thrombin time with the specific reagents of the system, as reported previously (Strandberg et al., 2016). We used the turbidometric method (Ellis and Stransky, 1961) to estimate the concentration of plasma fibrinogen. This involved measuring the rate of conversion of fibrinogen to fibrin in diluted plasma samples using thrombin.

\section{Statistical Analysis}

The design of this case-control study required the administration of the 2 treatments (camel milk and bovine milk) separately to healthy and diabetic animals, generating 4 groups. Negative control groups (receiving no treatment) were needed for the healthy and diabetic animals. As a result, we had 6 experimental groups, as detailed above. The data obtained were normally distributed and are presented as mean \pm standard deviation (SD). Statistical analysis was conducted using Prism 5.0 for Windows (Graph Pad Software Inc., San Diego, CA). The ANOVA test was used to compare the experimental groups with respect to each studied variable. When the ANOVA was significant, Tukey's post hoc test was applied. We also used paired sample $t$ tests to compare changes in a particular variable in the same group at different time points. Difference between results were considered significant at $P<0.05$.

\section{RESULTS}

\section{Body Weight Changes}

Increase in BW, whether in the control groups or the milk-treated diabetic animals, was a sign of good health and well-maintained glucose metabolism that led to the storage of energy as fatty tissue. In contrast, weight loss reflected disturbed glucose metabolism as a result of diabetes and insulin deficiency, and the animal's reliance on the consumption of body fat and protein as sources of energy, leading to BW loss. As Figure 1 shows, all study groups had comparable $(P>0.05)$ initial BW at wk 0 of the study. However, after 8 wk groups $\mathrm{C}$ and $\mathrm{CCM}$ showed a comparable $(P>0.05)$ increase in $\mathrm{BW}(216.80 \pm 13.93$ and $222.90 \pm 28.72 \mathrm{~g})$, which were $40 \%$ and $43.75 \%$ higher $(P<0.05)$ than their initial BW $(154.90 \pm 9.97$ and $160.60 \pm 9.57 \mathrm{~g})$. However, the CBM group showed a $69 \%$ weight gain by the end of the study, compared with initial BW (267.40 \pm 18.12 vs. $158.20 \pm 13.24 \mathrm{~g} ; P<0.05)$. These findings indicate that the healthy control animals gained more weight with bovine milk than with camel milk, possibly related to the total caloric value of each type of milk.

In contrast, group D showed an approximately $20 \%$ weight loss after 8 wk of the study compared with initial BW $(128.80 \pm 7.66$ vs. $160.6 \pm 6.06$ g; $P<0.05)$. However, improved glucose metabolism in the DCM group helped animals to resist the diabetes-induced weight loss, leading to a final BW increase of $10.2 \%$ compared with initial BW $(177.8 \pm 6.62$ vs. $161.30 \pm 6.01 \mathrm{~g} ; P<$ $0.05)$. The DBM group showed no significant difference in final BW compared with initial BW (157.10 \pm 13.12 vs. $162.50 \pm 9.96 \mathrm{~g})$. These findings reflected a better metabolic effect on energy balance and BW in the diabetic animals with camel milk than with bovine milk.

\section{Fasting Blood Glucose}

A normal FBG level reflects proper glucose homeostasis due to proper insulin secretion and function. In the 


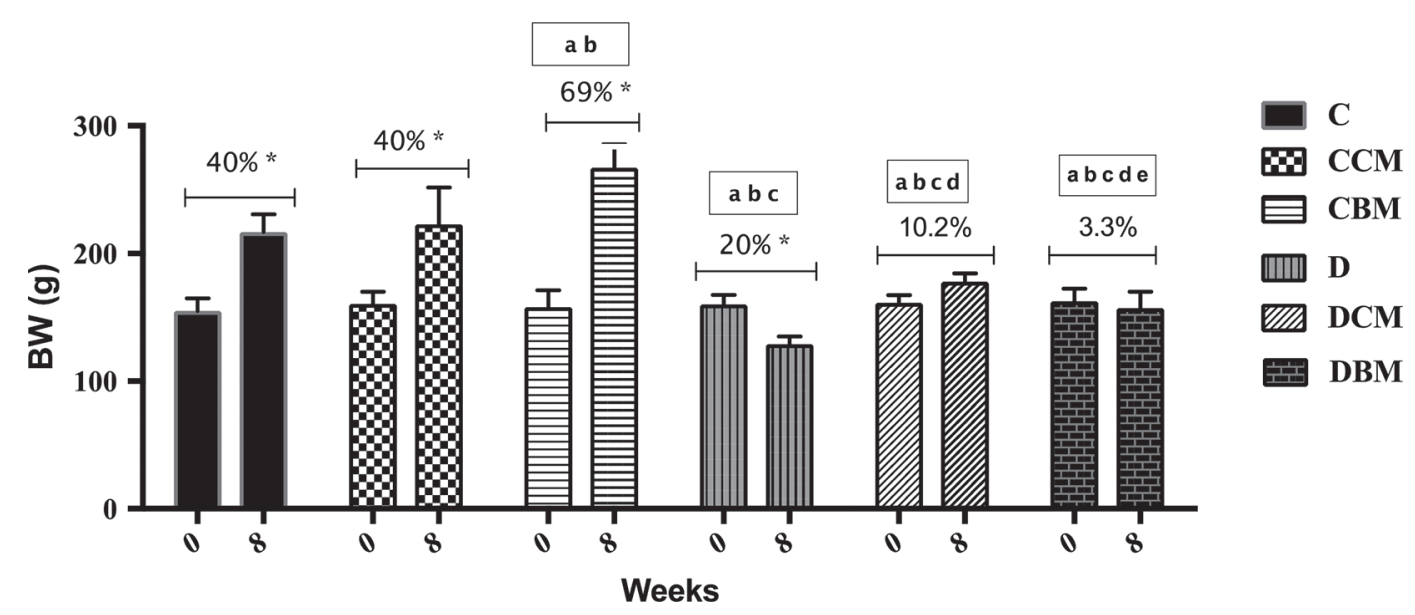

Figure 1. Body weight changes (mean $\pm \mathrm{SD}$; g) at the beginning (wk 0) and end (wk 8) of the study in the control (C), diabetic (D), camel milk-treated control (CCM), camel milk-treated diabetic (DCM), bovine milk-treated control (CBM), and bovine milk-treated diabetic (DBM) groups. ${ }^{*} P<0.5$ vs. wk 0 of the same group; ${ }^{a} P<0.05$ vs. $\mathrm{C},{ }^{\mathrm{b}} P<0.05$ vs. $\mathrm{CCM},{ }^{\mathrm{c}} P<0.05$ vs. $\mathrm{CBM},{ }^{\mathrm{d}} P<0.05$ vs. $\mathrm{D}$, and ${ }^{\mathrm{e}} P<0.05$ vs. DCM at the corresponding time points in the study.

healthy control groups C, CCM, and CBM, the FBG levels taken at 8 wk were comparable $(76.00 \pm 3.88$, $75.75 \pm 6.13$, and $79.45 \pm 11.40 \mathrm{mg} / \mathrm{dL}$, respectively; $P$ $>0.05)$ and showed no significant difference from the corresponding FBG levels at wk 0 (73.30 $\pm 3.16,74.30$ \pm 2.05 , and $74.09 \pm 2.77 \mathrm{mg} / \mathrm{dL}$; respectively; Figure 2). However, group D showed significant fasting hyperglycemia at wk 0 compared with group C (384.60 \pm 60.68 vs. $76.0 \pm 3.88 \mathrm{mg} / \mathrm{dL})$. Furthermore, after $8 \mathrm{wk}$ without specific treatment, the FBG of group D showed a $19 \%$ further increase $(456.60 \pm 111.90 \mathrm{mg} / \mathrm{dL} ; P<$ 0.05) compared with FBG at wk 0. It is noteworthy that camel milk treatment resulted in a significant reduction of FBG levels at wk 8 in group DCM compared with FBG at wk $0(142.50 \pm 68.20$ vs. $384.50 \pm 76.77$ $\mathrm{mg} / \mathrm{dL}$; Figure 2). Additionally, group DBM showed FBG at wk 8 that was significantly lower than the FBG at wk $0(234.80 \pm 33.96$ vs. $382.70 \pm 38.30 \mathrm{mg} / \mathrm{dL})$.

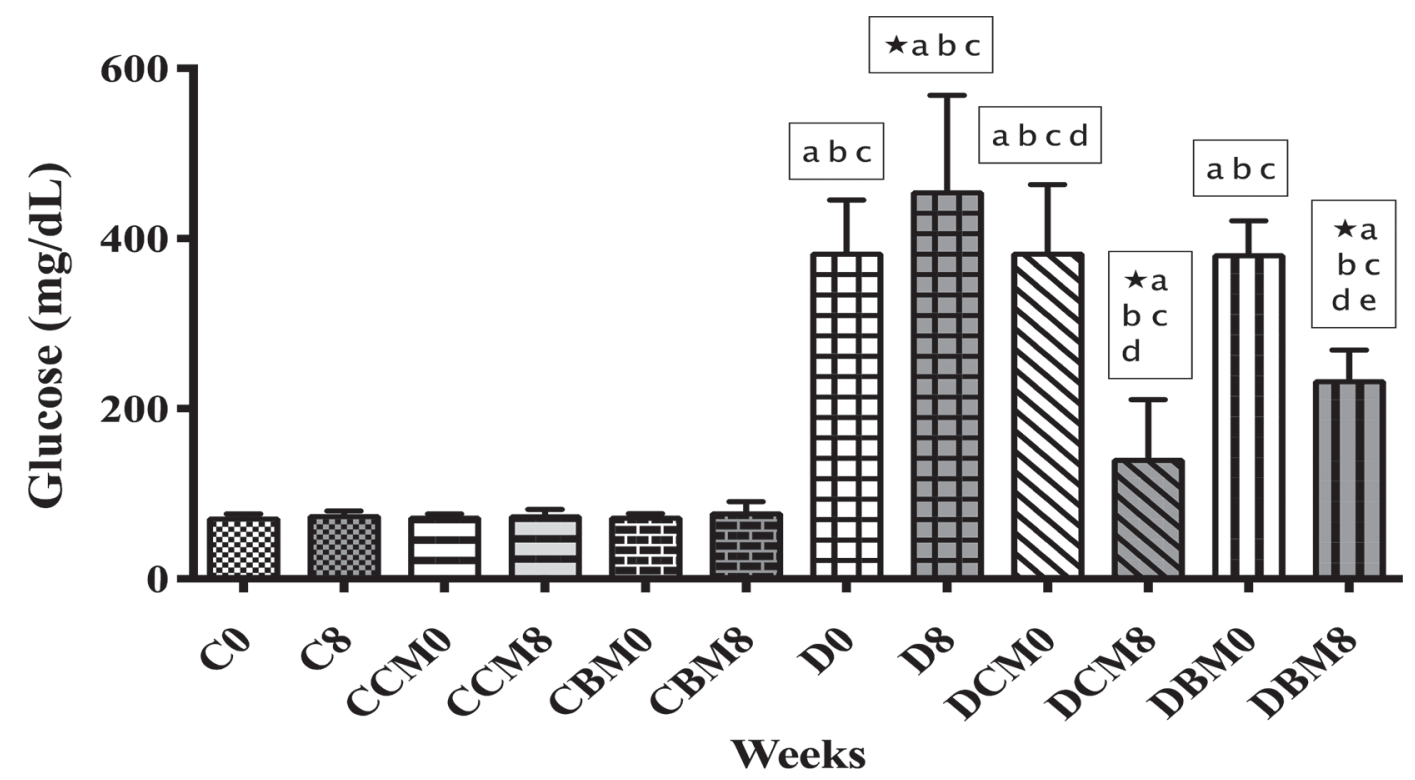

Figure 2. Changes in fasting blood glucose levels (mean $\pm \mathrm{SD} ; \mathrm{mg} / \mathrm{dL}$ ) at the beginning (wk 0) and end (wk 8) of the study in the control (C), diabetic (D), camel milk-treated control (CCM), camel milk-treated diabetic (DCM), bovine milk-treated control (CBM), and bovine milk-treated diabetic (DBM) groups. ${ }^{*} P<0.5$ vs. wk 0 of the same group; ${ }^{a} P<0.05$ vs. $\mathrm{C},{ }^{\mathrm{b}} P<0.05$ vs. CCM, ${ }^{\mathrm{c}} P<0.05$ vs. CBM, ${ }^{\mathrm{d}} P<0.05$ vs. D, and ${ }^{\mathrm{e}} P<0.05$ vs. DCM at the corresponding time points in the study. 
Interestingly, the hypoglycemic effect of camel milk in group DCM was significantly more potent than that of bovine milk in group DBM.

\section{Intraperitoneal Glucose Tolerance Test}

At the end of the 8 wk of the study, 0 min of the intraperitoneal GTT showed significant fasting hyperglycemia in group D compared with group C (437.60 \pm 98.89 vs. $76.00 \pm 3.88 \mathrm{mg} / \mathrm{dL}$; Figure 3$)$. The hyperglycemia in group D animals peaked at $556.90 \pm$ $89.65 \mathrm{mg} / \mathrm{dL}$ after $30 \mathrm{~min}$ of the intraperitoneal glucose load $(1 \mathrm{~g} / \mathrm{kg})$ and showed no significant decrease until 150 min of the test. This was a typical diabetic GTT test: it showed unabated hyperglycemia throughout the test, even before glucose was administered; the administration of glucose worsened the hyperglycemia. On the other hand, group DCM showed significant fasting hypoglycemia compared with group D (198.70 \pm 135.30 vs. $437.60 \pm 98.89 \mathrm{mg} / \mathrm{dL}$ ). Furthermore, the blood glucose of group DCM at time 0 showed no significance difference from the group $\mathrm{C}$ value. This clearly indicated the efficient antidiabetic action of camel milk treatment. However, at 15 min after the intraperitoneal glucose load was administered, group DCM started to show hyperglycemia compared with group C (322.9 \pm 160.4 vs. $122.40 \pm 35.54 \mathrm{mg} / \mathrm{dL} ; P<0.05$; Figure 3). Still, at 15 and $30 \mathrm{~min}$ of the GTT, the blood glucose levels of group DCM remained significantly lower than those of group D $(322.90 \pm 160.40$ and $382.30 \pm 136.70$ $\mathrm{mg} / \mathrm{dL}$, respectively, vs. $529.10 \pm 95.81$ and $556.90 \pm$ $89.65 \mathrm{mg} / \mathrm{dL}$, respectively), indicating some antidiabetic action of camel milk remaining in the rats' blood. This antidiabetic action of camel milk was totally lost at $60,90,120$, and $150 \mathrm{~min}$ of the GTT test: the blood glucose levels of group DCM showed no significant difference from those of group D (Figure 3).

Group DBM showed blood glucose levels at 0, 15, 30, 120, and 150 min that were significantly lower than those of group D, clearly indicating the efficacy of the

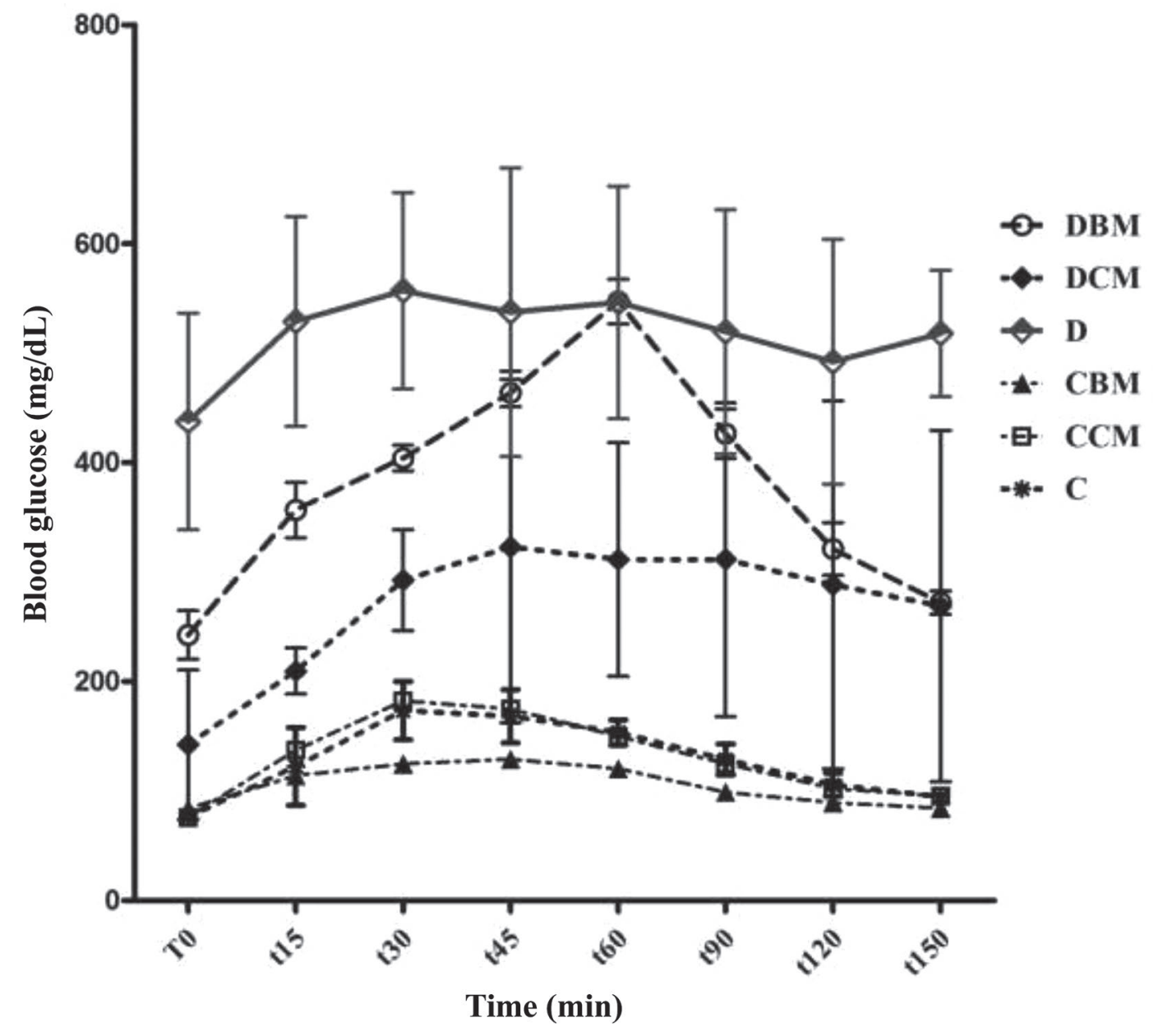

Figure 3. Intraperitoneal glucose tolerance curve (mean $\pm \mathrm{SD}$ ) at the end of the study in the control (C), diabetic (D), camel milk-treated control (CCM), camel milk-treated diabetic (DCM), bovine milk-treated control (CBM), and bovine milk-treated diabetic (DBM) groups. 
antidiabetic action of cow's milk throughout this period of the GTT. However, this efficacy was totally lost at 60 and 90 min: blood glucose levels in group DBM $(547.10 \pm 20.34 \mathrm{mg} / \mathrm{dL}$ and $428.10 \pm 20.03 \mathrm{mg} / \mathrm{dL}$, respectively), were not significantly different from those of group D.

The glucose tolerance curves of groups DBM and DCM were comparable throughout the test period (Figure 3). Chronic intake of camel or bovine milk by groups CCM and BCM caused no significant change in their glucose tolerance compared with group $\mathrm{C}$, which received no milk treatment (Figure 3 ).

\section{Platelet Aggregation Responses to ADP and Arachidonic Acid}

Platelets obtained from groups $\mathrm{C}$ and $\mathrm{D}$ responded poorly to activation by ADP $20 \mu \mathrm{mol} / \mathrm{L}(\mathrm{MA} \%=2.66$ \pm 1.86 and $1.25 \pm 0.46 \%$, respectively; Figure $4 \mathrm{~A}$ ). To ensure the efficacy of ADP, the same dose of ADP triggered irreversible aggregation responses of controls in human platelet-rich plasma $(\mathrm{MA} \%=60.1 \pm 10.4 \%)$. However, platelets from group DCM displayed aggregation responses to ADP that were stronger than the platelets obtained from group CCM (MA\% $=34.16 \pm$ 11.40 vs. $21.00 \pm 9.79 \% ; P<0.001$ ). Interestingly, the administration of bovine milk resulted in higher $(P<$ 0.05) platelet aggregation response to ADP in group DBM than in group DCM $(\mathrm{MA} \%=48.71 \pm 19.38$ vs. $34.16 \pm 11.40 \%)$. This finding indicates clearly that bovine milk has stronger anticoagulant action than camel milk, preventing STZ-triggered coagulopathy and its associated loss of platelet responses (Figure 4A).

Arachidonic acid failed to trigger aggregation responses in the platelets prepared from the STZ-induced diabetic group D $(\mathrm{MA} \%=3.13 \pm 1.80 \%)$, but the administration of camel milk or bovine milk in groups CCM and CBM triggered significant and comparable platelet aggregation responses to arachidonic acid $(\mathrm{MA} \%=56.41 \pm 11.52$ and $52.25 \pm 8.18 \%$, respectively), and these responses were not significantly different from those obtained in group C (MA\% $=41.33 \pm$ $9.30 \%$; Figure 4B). Treatment of the diabetic animals with camel milk or bovine milk resulted in the recovery of the absent platelet aggregation responses to arachidonic acid; however, the responses to bovine milk were more pronounced than for camel milk (MA\% $=71.11$ \pm 24.95 vs. $52.08 \pm 7.95 \% ; P<0.001$ ), confirming the more potent anticoagulant action of bovine milk than camel milk that was obtained above for the ADP aggregation responses. Notably, the aggregation response in the DBM group was higher $(P<0.001)$ than for groups C, CCM, and CBM (Figure 4B).

\section{Plasma Fibrinogen}

The induction of diabetes after the administration of STZ in rats resulted in significant consumption of fibrinogen, after which levels dropped to $105.06 \pm 67.73$ $\mathrm{mg} / \mathrm{dL}(P<0.0001)$, compared with control levels of $247.80 \pm 57.43 \mathrm{mg} / \mathrm{dL}$ (Figure 5). This massive drop in plasma fibrinogen can only be accounted for by activation of the coagulation system at a similar scale that ended in the generation of thrombin. Thrombin changes the soluble plasma protein fibrinogen to fibrin,
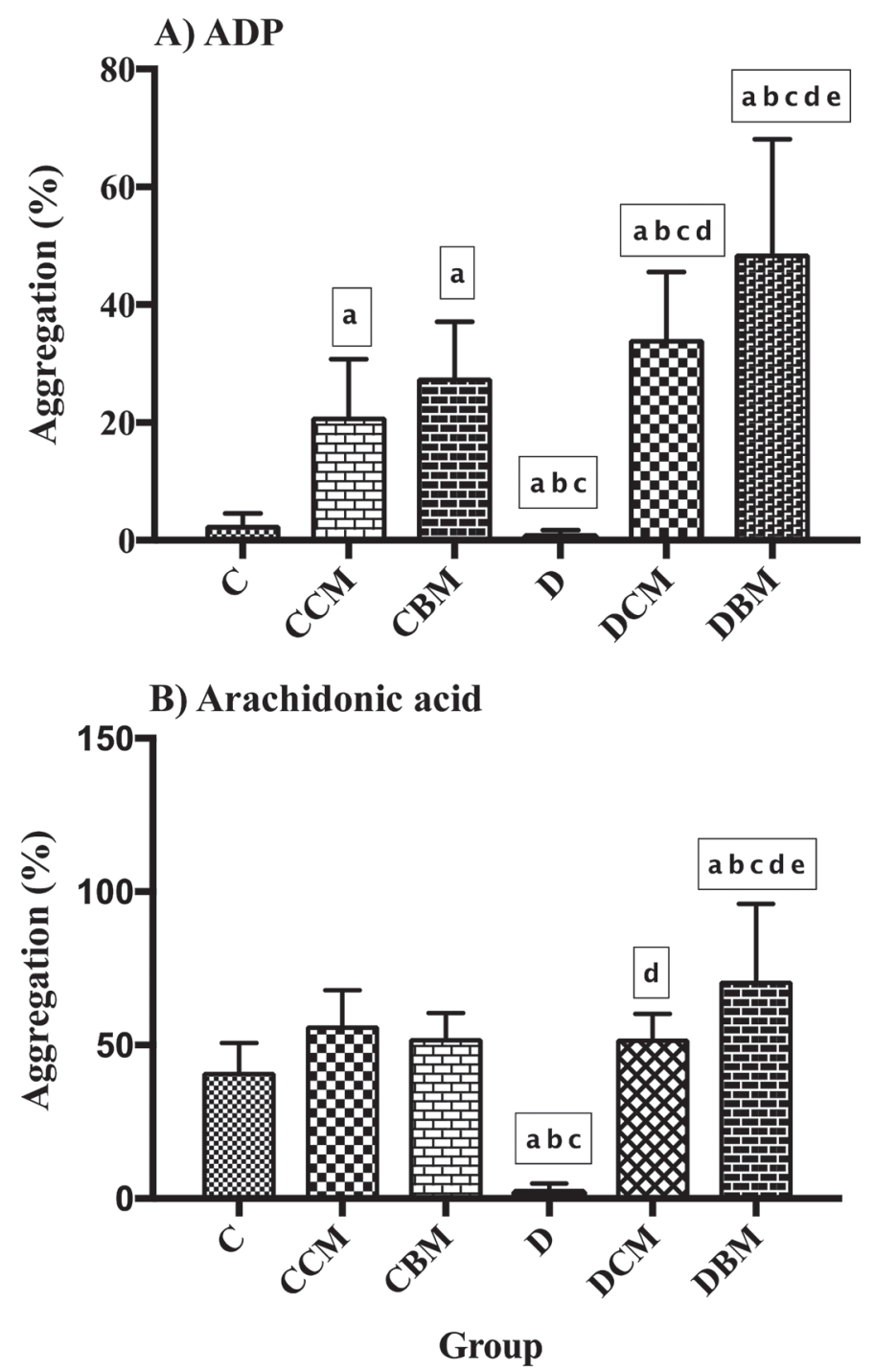

Figure 4. Platelet aggregation response (mean $\pm \mathrm{SD}$ ) to $20 \mu \mathrm{mol} / \mathrm{L}$ (A) ADP and (B) arachidonic acid stimulation at the end (wk 8) of the study in the control $(\mathrm{C})$, diabetic (D), camel milk-treated control $(\mathrm{CCM})$, camel milk-treated diabetic (DCM), bovine milk-treated control (CBM), and bovine milk-treated diabetic (DBM) groups. ${ }^{a} P<$ 0.05 vs. $\mathrm{C},{ }^{\mathrm{b}} P<0.05$ vs. $\mathrm{CCM},{ }^{\mathrm{c}} P<0.05$ vs. $\mathrm{CBM},{ }^{\mathrm{d}} P<0.05$ vs. $\mathrm{D}$, and ${ }^{\mathrm{e}} P<0.05$ vs. DCM at the corresponding time points in the study. 
which features in the massive drop of levels in plasma. However, the administration of both camel milk and bovine milk in diabetic hypofibrinogenic rats resulted in a remarkable recovery of fibrinogen levels $(P<0.0001)$, which reached a mean plasma level of $196.71 \pm 57.06$ $\mathrm{mg} / \mathrm{dL}$ after camel milk administration and even higher levels after bovine milk treatment $(231.87 \pm 60.89 \mathrm{mg} /$ $\mathrm{dL} ; P<0.0001)$. It is quite clear that bovine milk has more potent anticoagulant action than camel milk, judging by its effect in blunting STZ-induced fibrinogen consumption.

\section{APTT}

The APTT coagulation test screens for integrity of the intrinsic pathway of the coagulation system and the maintenance of satisfactory levels of the coagulation factors that participate in it. We found that APPT was shortened $(P<0.001)$ in group D $(22.32 \pm 2.78)$, as well as in groups DCM and DBM $(21.66 \pm 2.85$ and $21.04 \pm 3.72 \mathrm{~s}$, respectively) compared with group C $(25.83 \pm 5.61 \mathrm{~s} ;$ Figure 6$)$. The shortened APTT in diabetic animals with or without camel milk or bovine milk treatment suggested some degree of overall activation of the coagulation system that was not affected by the anticoagulant action of either camel or bovine milk.

\section{DISCUSSION}

The current study in rats with STZ-induced diabetes aimed at comparing the effects of camel and bovine milk on glucose homeostasis, blood coagulation, and platelet function. A search in the literature did not identify any similar studies in which the hypoglycemic and antithrombotic actions of both camel milk and bovine milk were compared in the same setting.

It has repeatedly been shown that the consumption of camel milk results in significant drop in blood glucose levels and a reduction in insulin requirements, in people with diabetes and experimental animals (Agrawal et al., 2003, 2004). Our current findings of the more potent hypoglycemic action of camel milk compared with bovine milk, can be attributed to many factors. First, the total concentration of insulin in camel milk (58.67 $\mathrm{IU} / \mathrm{L})$ is more than 3 times that of bovine milk (17.0 IU/L; Hamad et al., 2011). Further, although camel milk insulin is peptide in nature, it exhibits its hypoglycemic action when given orally, as it resists destruction by gastric acidity and intestinal enzymes because it is encapsulated in nanoparticles (lipid micelles); it escapes digestion and remains available for intestinal absorption (Malik et al., 2012). This unique characteristic of camel milk insulin gives it an advantage over other mammalian insulin and could support its therapeutic value

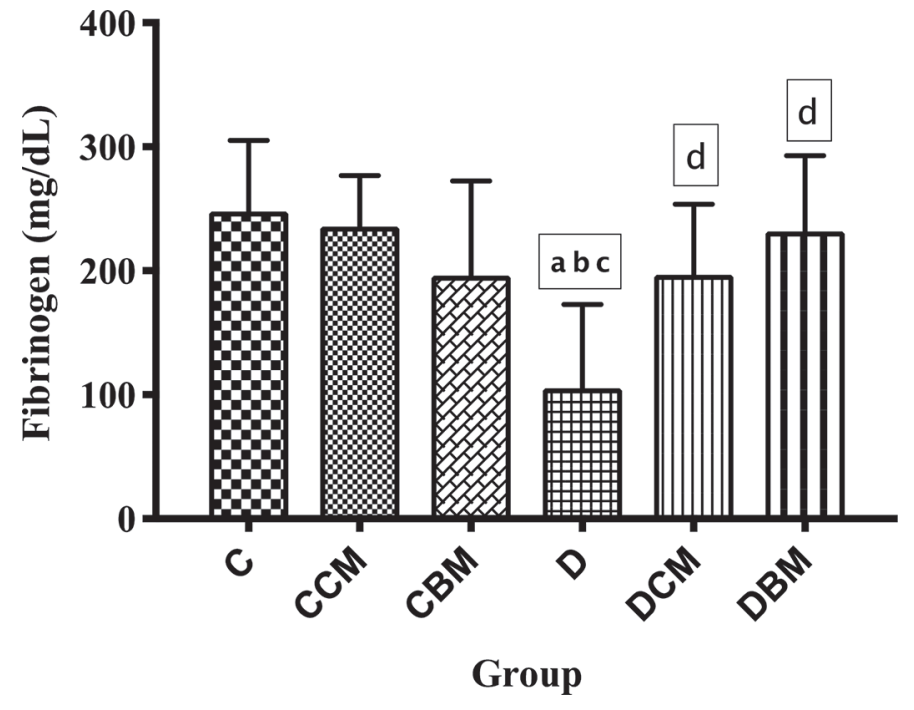

Figure 5. Plasma fibrinogen levels (mean $\pm \mathrm{SD} ; \mathrm{mg} / \mathrm{dL}$ ) at the end (wk 8) of the study in the control (C), diabetic (D), camel milktreated control (CCM), camel milk-treated diabetic (DCM), bovine milk-treated control (CBM), and bovine milk-treated diabetic (DBM) groups. ${ }^{\mathrm{a}} P<0.05$ vs. $\mathrm{C},{ }^{\mathrm{b}} P<0.05$ vs. $\mathrm{CCM},{ }^{\mathrm{c}} P<0.05$ vs. $\mathrm{CBM}$, and ${ }^{\mathrm{d}} P<0.05$ vs. D at the corresponding time points in the study.

in people with diabetes when given orally. Second, a group of researchers from the United Arab of Emirates and Ireland recently identified novel peptides in camel milk hydrolysates that inhibit dipeptidyl peptidase-4 (Mudgil et al., 2018; Nongonierma et al, 2018, 2019). This enzyme plays a major role in glucose metabolism

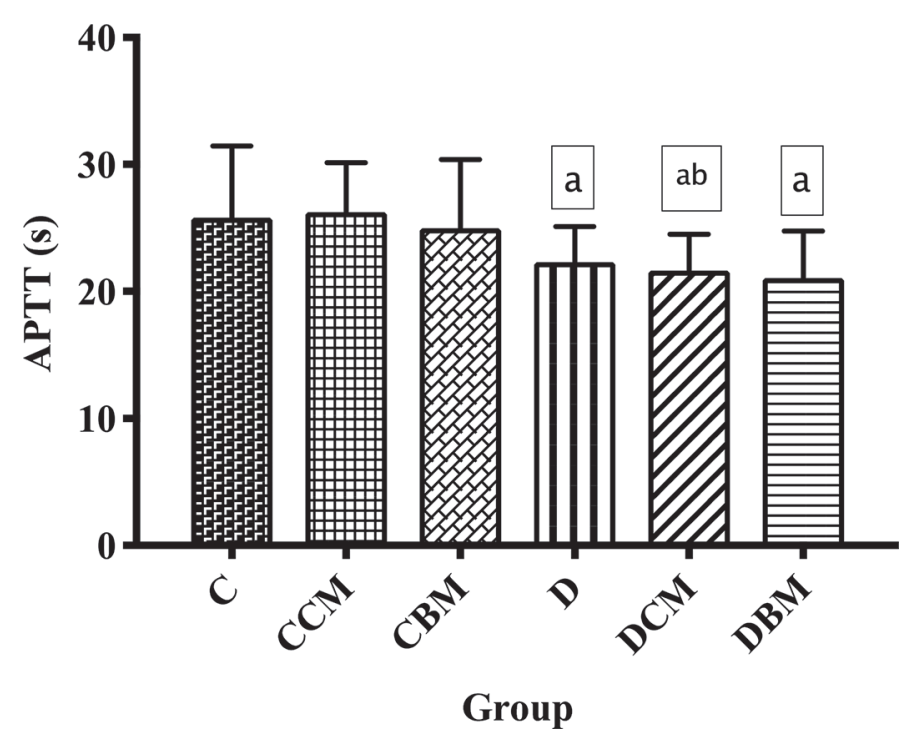

Figure 6. Activated partial thromboplastin time (APTT; mean $\pm \mathrm{SD} ; \mathrm{s}$ ) at the end (wk 8) of the study in the control (C), diabetic (D), camel milk-treated control (CCM), camel milk-treated diabetic (DCM), bovine milk-treated control (CBM), and bovine milk-treated diabetic (DBM) groups. ${ }^{\mathrm{a}} P<0.05$ vs. $\mathrm{C},{ }^{\mathrm{b}} P<0.05$ vs. CCM. 
by degrading gut hormones and incretins (Nauck and Meier, 2018), resulting in improved glucose-dependent insulin secretion and reduced inappropriate glucagon secretion. Interestingly, camel milk hydrolysates have been shown to possess higher dipeptidyl peptidase-4 inhibition than bovine milk protein hydrolysates (Nongonierma et al., 2017) and this, in part, account for our finding of a more potent hypoglycemic action of camel milk compared with bovine milk and explains the increased serum incretin levels in diabetic animals receiving oral camel milk (Korish, 2014). These milkderived bioactive peptides are believed to play a major role in glucose homeostasis and in the antidiabetic effect of camel milk. Third, camel milk has high zinc content, which acts as an active stimulant to the insulin secretary activity of the pancreatic $\beta$-cells (Park and Haenlein, 2013).

Regarding the molecular mechanisms responsible for the hypoglycemic action of camel milk, Abdulrahman et al. (2016) have recently shown that camel milk has direct effect on insulin receptor conformation and activation, with differential effects on intracellular signaling, enhancing glucose uptake by insulin-sensitive tissues. Furthermore, immunoglobulin antibodies in camel milk may induce immunoregulatory cells that can downregulate the immune system and $\beta$-cell salvage (Baheti et al., 2014). Therefore, some investigators have proposed the immunomodulatory theory in explaining the health benefits of camel milk in diseases with an immunologic background, including diabetes mellitus (Abdulrahman et al., 2016).

As to the hypoglycemic action of bovine milk, it has been recently reported that 10 wk of administration of $\alpha$-lactalbumin derived from bovine milk in diabetic animals suppressed inflammatory prostaglandin E, increased levels of high-molecular-weight adiponectin, and improved glucose tolerance without affecting insulin release (Yamaguchi and Takai, 2014). As well, the administration of bovine milk whey proteins to Goto-Kakizaki rats, known to be glucose intolerant, enhanced their response to exogenous insulin (Yamaguchi and Takai, 2014).

The other aspect of the current study dealt with the anticoagulant (antithrombotic) actions of camel milk and bovine milk. We have recently reported that camel milk has a significant anticoagulant (antithrombotic) action, preventing fibrinogen consumption and sustaining platelet function in the STZ rat model of diabetes (Korish et al., 2015). However, the important additional new finding of the current study is that whole bovine milk has similar but more potent effects than camel milk, preventing fibrinogen consumption and sustaining platelet function. The degradation and consumption of plasma fibrinogen along with the loss of platelet activity, as reflected by inhibited platelet aggregation response, are both features of the activation of the coagulation system in vivo, resulting in a consumption coagulopathy, which is known to follow the administration of STZ in rats (Okazaki et al., 1997). However, numerous published reports exist on the anticoagulant (antithrombotic) action of derivatives of bovine milk, especially casein ( $\kappa$-casein; Manso et al., 2002; Sultan et al., 2018) and lactoferrin (Shi and Gilbert, 2003). Whole bovine milk, rather than its derivatives, is available widely for human consumption, and our findings confirm a further health benefit for consumers.

Bioactive dietary derivatives are defined as "a food component that can affect biological processes or substrates and, hence, have an effect on the body function or condition and ultimately health" (Bhat et al., 2015). A further characteristic feature of these substances is that they should give a measurable biological effect using laboratory or other methods relevant to its presumed biological and probable medicinal action in humans. With these basic principles in mind, and as mentioned earlier, some researchers have shown that bioactive peptides usually encrypted in bovine milk proteins (and bovine dairy products), casein, and whey proteins, had anticoagulant (antithrombotic) action (Marcone et al., 2017). These peptides are inactive in the "mother" protein sequence. They require release from their protein precursors by digestive enzyme proteolysis or hydrolysis in the gastrointestinal tract (Chabance et al., 1995).

It is also has been established that the most important antithrombotic peptides, casoplatelin (Fiat et al., 1993) and casopiastrin (Manso et al., 2002), are derived from bovine $\kappa$-casein. Their main action is inhibiting platelet aggregation by preventing the binding of fibrinogen to its glycoprotein receptors $(\alpha \operatorname{IIb} \beta 3)$ on the platelet cell membrane. These peptides can be detected in the plasma of infants after consuming cow-based infant formula or after breastfeeding (Chabance et al., 1995). Similar homologies have been shown between the bovine short peptide (KRDS sequence) derived from bovine milk $\kappa$-casein and RGDS sequence derived from human lactoferrin, both with similar antiplatelet/ antithrombotic activity (Drouet et al., 1990; Marcone et al., 2017). Other researchers have confirmed the presence of at least 1 short peptide (KDQDK) in bovine milk that inhibited platelet aggregation and thrombin generation (Marcone et al., 2017). This, in addition to the similarities in the antiplatelet/antithrombotic activities of bioactive peptides derived from bovine and caprine $\kappa$-casein (Manso et al., 2002; Marcone et al., 2017) makes it possible to suggest that this similarity could be extended to include bioactive peptides present in camel $\kappa$-casein that are waiting to be identified 
and studied. Accordingly, the existence of antiplatelet/ antithrombotic peptides originating from camel milk, similar to the bovine bioactive peptides discussed above, could explain the observed antiplatelet/antithrombotic actions of camel milk demonstrated in the current study.

It is worth adding a short note on the observed depressed platelet aggregation responses associated with hemostatic activation and the consumption of fibrinogen in STZ-induced diabetic animals. Okazaki et al., (1997) reported that the administration of STZ in rats, in addition to the induction of diabetes, also triggers significant consumption coagulopathy and depletion of the circulating fibrinogen. In line with this observation, in an earlier publication on consumption coagulopathy in patients with heat stroke, we observed initial platelet activation, consumption coagulopathy, significant depletion of fibrinogen, and very depressed platelet aggregation response (Gader et al., 1990). Interestingly, this platelet activation process can be prevented by antiplatelet therapy (Al-Mashhadani et al., 1997). Thus, the reversal of a similar hemostatic activation process by camel milk in the STZ rat model can only be explained by the effect of bioactive antithrombotic components present in ingested camel milk, in the same manner as the bovine milk reported in the literature and discussed above. However, camel milk biological properties have attracted attention only, recently and its detailed composition has been reported by our group (Alhaider et al., 2013).

The identified camel milk proteins and peptides displayed homology with bovine peptides encoded in the backbone of major proteins; others were characterized by de novo sequencing of tandem mass spectra (Alhaider et al., 2013). Similar to bovine milk, some of the camel milk peptides are certain to display (in addition to antiplatelet/antithrombotic effects) antimicrobial properties, antifungal properties, blood pressure-lowering effects, cholesterol-lowering effects, and immunomodulatory effects (Park and Haenlein, 2013; Baheti et al., 2014; Aref, 2018), as has already been established for bioactive peptides isolated from bovine milk. Similar bioactive peptides will soon be identified in camel milk.

Wide interest in camel milk has emerged only recently, with more widespread information about its health benefits, and that presumably has led to the growing popularity of camel milk in Western countries. European countries are now importing camel milk from the United Arab Emirates (European Union, 2013), and the number of camel dairy farms has been increasing in the United States since the Food and Drug Administration approved the sale of camel milk in American supermarkets (Camel Milk USA, 2015).
Finally, blood platelets are now recognized to be the central cells involved in normal hemostasis and in the etiology of thrombotic vascular occlusive diseases (Hou et al., 2015). The drug industry has generated a wide variety of chemotherapeutic agents that have led to marked reductions in morbidity and mortality from these diseases, but their benefit is sometimes associated with serious bleeding complications (Deshpande et al., 2018). The elaboration of nonpharmacological therapies could offer an alternative with better outcomes to people with vascular occlusive diseases. In this respect, camel and bovine bioactive peptides are in a good position to be used as such alternative natural therapies in humans. Furthermore, these food-derived natural peptides, with few side effects and readily absorbed from the gastrointestinal tract, could be of commercial interest. It is no surprise that they are attracting a great deal of attention from the pharmaceutical and the health-promoting functional food industries (Chakrabarti et al., 2018).

One limitation of this study is that we did not perform specific tests of consumption coagulopathy as conducted by (Okazaki et al., 1997). As well, no in vivo studies have been conducted in humans to test the claimed biological/medical benefits of camel milk on hemostasis. This could be undertaken in future studies.

\section{CONCLUSIONS}

Streptozotocin is known to trigger a slow activation of coagulation, resulting in the consumption of circulating fibrinogen and loss of platelet aggregation. In the current study, we found that bovine milk was more effective in preventing the consumption of fibrinogen and restoring platelet aggregation response than camel milk. The treatment of diabetic rats with either camel milk or bovine milk resulted in significant weight gain, decreased blood glucose levels, and improved glucose tolerance; however, the antidiabetic action of camel milk was more pronounced than that of bovine milk. More studies are needed to identify the specific peptides responsible for this antiplatelet/antithrombotic effects of camel milk, uncover the molecular mechanisms involved, and establish the homology, if any, that exists between these camel milk peptides and those already identified and characterized in human and bovine milk.

\section{ACKNOWLEDGMENTS}

The authors thank J. A. Hardallo (Pharmacology Department, College of Medicine, King Saud University, Riyadh, Saudi Arabia) and M. A. Hamid and L. G. El-Sid (Coagulation Research Laboratory, Physiology Department, College of Medicine, King Saud 
University) for their technical assistance. This research project was supported by a grant from the Research Center of the Center for Female Scientific and Medical Colleges Deanship of Scientific Research, King Saud University. This work is dedicated to our colleague and co-researcher A. A. Alhaider, who passed away during the preparation of this manuscript.

\section{REFERENCES}

Abdulrahman, A. O., M. A. Ismael, K. Al-Hosaini, C. Rame, A. M. Al-Senaidy, J. Dupont, and M. A. Ayoub. 2016. Differential effects of camel milk on insulin receptor signaling - toward understanding the insulin-like properties of camel milk. Front. Endocrinol. (Lausanne) 7:4.

Abera, T., Y. Legesse, B. Mummed, and B. Urga. 2016. Bacteriological quality of raw camel milk along the market value chain in Fafen zone, Ethiopian Somali regional state. BMC Res. Notes 9:285.

ADA (American Diabetes Association). 2014. Diagnosis and classification of diabetes mellitus. Diabetes Care 37(Suppl. 1):S81-S90.

Agrawal, R. P., D. K. Kochar, M. S. Sahani, F. C. Tuteja, and S. K. Ghorui. 2004. Hypoglycemic activity of camel milk in streptozotocin induced diabetic rats. Int. J. Diabetes Dev. Ctries. 24:47-49.

Agrawal, R. P., S. C. Swami, R. Beniwal, D. K. Kochar, M. S. Sahani, F. C. Tuteja, and S. K. Ghorui. 2003. Effect of camel milk on glycemic control, lipid profile and diabetes quality of life in type 1 diabetes: A randomized prospective controlled cross over study. Indian J. Anim. Sci. 73:1105-1110.

Al-Mashhadani, S. A., A. M. Gader, and S. Al Harthi. 1997. The role of platelets in the coagulopathy of heatstroke a study of platelet aggregation in heatstroke patients during the Makkah pilgrimage (Haj). Platelets 8:37-42.

Alhaider, A., A. G. Abdelgader, A. A. Turjoman, K. Newell, S. W. Hunsucker, B. Shan, B. Ma, S. W. Hunsucker, and M. W. Duncan. 2013. Through the eye of an electrospray needle: Mass spectrometric identification of the major peptides and proteins in the milk of the one-humped camel (Camelus dromedarius). J. Mass Spectrom. 48:779-794.

Angiolillo, D. J., A. Fernandez-Ortiz, E. Bernardo, F. Alfonso, C. Macaya, T. A. Bass, and M. A. Costa. 2007. Variability in individual responsiveness to clopidogrel: Clinical implications, management, and future perspectives. J. Am. Coll. Cardiol. 49:1505-1516.

AOAC International. 2000. Official Methods of Analysis. 17th ed. AOAC International, Gaithersburg, MD.

AOCS. 1998. Official Methods and Recommended Practices of the American Oil Chemists' Society. 5th ed. D. Firestone, ed. American Oil Chemists' Society, Urbana, IL.

Aref, A. R. 2018. Camel milk as a complementary and alternative medicine. Int. J. Sci. Res. (Ahmedabad) 7:435-439.

Baheti, W., H. Liu, and N. Xin-Hua. 2014. Evaluation of immunomodulatory effects of bioactive peptides derived from fermented camel milk on splenocytes proliferation. Zhongguo Rupin Gongye 42:15-17.

Bhat, Z. F., S. Kumar, and H. F. Bhat. 2015. Bioactive peptides of animal origin: A review. J. Food Sci. Technol. 52:5377-5392.

Chabance, B., P. Jollès, C. Izquierdo, E. Mazoyer, C. Francoual, L. Drouet, and A. M. Fiat. 1995. Characterization of an antithrombotic peptide from $\alpha$-casein in newborn plasma after milk ingestion. Br. J. Nutr. 73:583-590.

Chakrabarti, S., S. Guha, and K. Majumder. 2018. Food-derived bioactive peptides in human health: Challenges and opportunities. Nutrients 10:E1738

European Union. 2013. Commission Implementing Regulation (EU) No 300/2013 of 27 March 2013 amending Regulation (EU) No $605 / 2010$ laying down animal and public health and veterinary certification conditions for the introduction into the European Union of raw milk and dairy products intended for human con- sumption (OJ L 90, 28.3.2013, p. 71). https://eur-lex.europa.eu/ legal-content/EN/TXT/?uri=CELEX\%3A32018R0083.

Deshpande, N. V., P. Admane, and H. M. Mardikar. 2018. Bleeding on dual antiplatelet therapy: Real-life challenges. Eur. Heart J. Suppl. 20(Suppl. B):B1-B9.

Camel Milk USA. 2015. Dr. Hinkle wins FDA approval for sale of camel milk. Accessed Sep. 16, 2019. www.camelmilkusa.com/index .../dr-hinkle-wins-fda-approval-for-sale-of-camel-milk/.

Drouet, L., M. Cisse, G. Pignaud, E. Mazoyer, A. M. Fiat, P. Jolles, and J. P. Caen. 1990. The antithrombotic effect of KRDS, a lactotransferrin peptide, compared with RGDS. Nouv. Rev. Fr. Hematol. 32:59-62.

Ellis, B. C., and A. Stransky. 1961. A quick and accurate method for the determination of fibronogen in plasma. J. Lab. Clin. Med. $58: 477-488$

Fiat, A. M., D. Migliore-Samour, P. Jolles, L. Drouet, C. B. D. Sollier, and J. Caen. 1993. Biologically active peptides from milk proteins with emphasis on two examples concerning antithrombotic and immunomodulating activities. J. Dairy Sci. 76:301-310.

Gader, A. G. M. A., and A. A. Alhaider. 2016. The unique medicinal properties of camel products: A review of the scientific evidence. J. Taibah Univ. Med. Sci. 11:98-103.

Gader, A. M. A., S. A. Al-Mashhadani, and S. S. Al-Harthy. 1990. Direct activation of platelets by heat is the possible trigger of the coagulopathy of heat stroke. Br. J. Haematol. 74:86-92.

Hamad, E. M., E. A. Abdel-Rahim, and E. A. Romeih. 2011. Beneficial effect of camel milk on liver and kidneys function in diabetic Sprague-Dawley rats. Int. J. Dairy Sci. 6:190-197.

Hou, Y., N. Carrim, Y. Wang, R. C. Gallant, A. Marshall, and H. Ni. 2015. Platelets in hemostasis and thrombosis: Novel mechanisms of fibrinogen-independent platelet aggregation and fibronectinmediated protein wave of hemostasis. J. Biomed. Res. 29:437-444.

Kakouros, N., J. J. Rade, A. Kourliouros, and J. R. Resar. 2011. Platelet function in patients with diabetes mellitus: From a theoretical to a practical perspective. Int. J. Endocrinol. 2011:742719.

Karuna, R., V. G. Bharathi, S. S. Reddy, B. Ramesh, and D. Saralakumari. 2011. Protective effects of Phyllanthus amarus aqueous extract against renal oxidative stress in Streptozotocin-induced diabetic rats. Indian J. Pharmacol. 43:414-418.

Korish, A. A. 2014. The antidiabetic action of camel milk in experimental type 2 diabetes mellitus: An overview on the changes in incretin hormones, insulin resistance, and inflammatory cytokines. Horm. Metab. Res. 46:404-411.

Korish, A. A., A. G. M. Abdel Gader, and A. A. Alhaider. 2015. Camel milk ameliorates the coagulopathy in streptozotocin diabetic rat model. Int. J. Dairy Technol. 68:79-87.

Low Wang, C. C., C. N. Hess, W. R. Hiatt, and A. B. Goldfine 2016. Clinical update: Cardiovascular disease in diabetes mellitus: Atherosclerotic cardiovascular disease and heart failure in type 2 diabetes mellitus-mechanisms, management, and clinical considerations. Circulation 133:2459-2502.

Lowry, O. H., N. J. Rosebrough, A. L. Farr, and R. J. Randall. 1951. Protein measurement with Folin phenol reagent. J. Biol. Chem. 193:265-275.

Malik, A., A. Al-Senaidy, E. Skrzypczak-Jankun, and J. Jankun. 2012. A study of the anti-diabetic agents of camel milk. Int. J. Mol. Med. 30:585-592.

Manso, M. A., C. Escudero, M. Alijo, and R. López-Fandiño. 2002. Platelet aggregation inhibitory activity of bovine, ovine, and caprine $\kappa$-casein macropeptides and their tryptic hydrolysates. J. Food Prot. 65:1992-1996.

Marcone, S., O. Belton, and D. J. Fitzgerald. 2017. Milk-derived bioactive peptides and their health promoting effects: A potential role in atherosclerosis. Br. J. Clin. Pharmacol. 83:152-162.

Mudgil, P., H. Kamal, G. C. Yuen, and S. Maqsood. 2018. Characterization and identification of novel antidiabetic and anti-obesity peptides from camel milk protein hydrolysates. Food Chem.259:46-54

Nauck, M. A., and J. J. Meier. 2018. Incretin hormones: Their role in health and disease. Diabetes Obes. Metab. 20:5-21. 
Nicolucci, A., and E. Standl. 2011. Antiplatelet therapy for every diabetic person? Diabetes Care 34(Suppl. 2):S150-S154.

Nongonierma, A. B., C. Cadamuro, A. Le Gouic, P. Mudgil, S. Maqsood, and R. J. FitzGerald. 2019. Dipeptidyl peptidase IV (DPPIV) inhibitory properties of a camel whey protein enriched hydrolysate preparation. Food Chem. 279:70-79.

Nongonierma, A. B., S. Paolella, P. Mudgil, S. Maqsood, and R. J. FitzGerald. 2017. Dipeptidyl peptidase IV (DPP-IV) inhibitory properties of camel milk protein hydrolysates generated with trypsin. J. Funct. Foods 34:49-58.

Nongonierma, A. B., S. Paolella, P. Mudgil, S. Maqsood, and R. J. FitzGerald. 2018. Identification of novel dipeptidyl peptidase IV (DPP-IV) inhibitory peptides in camel milk protein hydrolysates. Food Chem. 244:340-348.

Ogawa, H., M. Nakayama, T. Morimoto, S. Uemura, M. Kanauchi, N. Doi, H. Jinnouchi, S. Sugiyama, Y. Saito, Japanese Primary Prevention of Atherosclerosis With Aspirin for Diabetes (JPAD) Trial Investigators. 2008. Low-dose aspirin for primary prevention of atherosclerotic events in patients with type 2 diabetes: a randomized controlled trial. JAMA 300:2134-2141.

Okazaki, M., H. Zhang, M. Tsuji, Y. Morio, and K. K. Oguchi. 1997. Blood coagulability and fibrinolysis in streptozotocin-induced diabetic rats. J. Atheroscler. Thromb. 4:27-33.

Omer, A., V. F. Duvivier-Kali, W. Aschenbach, V. Tchipashvili, L. J. Goodyear, and G. Weir. 2004. Exercise induces hypoglycemia in rats with islet transplantation. Diabetes 53:360-365.

Otero, P., B. Bonet, E. Herrera, and A. Rabano. 2005. Development of atherosclerosis in the diabetic BALB/c mice: Prevention with vitamin E administration. Atherosclerosis 182:259-265.

Paneni, F., J. A. Beckman, M. A. Creager, and F. Cosentino. 2013. Diabetes and vascular disease: Pathophysiology, clinical consequences, and medical therapy: Part I. Eur. Heart J. 34:2436-2443.
Park, Y. W., and G. F. Haenlein, ed. 2013. Milk and Dairy Products in Human Nutrition: Production, Composition and Health. John Wiley and Sons, Hoboken, NJ.

Rao, M. B., R. C. Gupta, and N. N. Dastur. 1970. Camels' milk and milk products. Indian J. Dairy Sci. 23:71-78.

Sarfraz, L. 2014. Effect of camel milk supplementation on blood parameters and liver function of hepatitis patients. Am. J. Ethnomed. 1:129-146.

Shi, J., and G. E. Gilbert. 2003. Lactadherin inhibits enzyme complexes of blood coagulation by competing for phospholipid-binding sites. Blood 101:2628-2636.

Strandberg, G., M. Lipcsey, M. Eriksson, N. Lubenow, and A. Larsson. 2016. Analysis of thromboelastography, PT, APTT and fibrinogen in intraosseous and venous samples - an experimental study. Scand. J. Trauma Resusc. Emerg. Med. 24:131.

Sultan, S., N. Huma, M. S. Butt, M. Aleem, and M. Abbas. 2018. Therapeutic potential of dairy bioactive peptides: A contemporary perspective. Crit. Rev. Food Sci. Nutr. 58:105-115.

Yamaguchi, M., and S. Takai. 2014. Chronic administration of bovine milk-derived $\alpha$-lactalbumin improves glucose tolerance via enhancement of adiponectin in Goto-Kakizaki rats with type 2 diabetes. Biol. Pharm. Bull. 37:404-408.

\section{ORCIDS}

Aida A. Korish ๑ https://orcid.org/0000-0002-4650-0882 